\title{
Morphology-Tailored Synthesis of Tungsten Trioxide (Hydrate) Thin Films and Their Photocatalytic Properties
}

\author{
Zhihui Jiao, ${ }^{\dagger}$ Jinmin Wang, ${ }^{\dagger}$ Lin Ke, ${ }^{\ddagger}$ Xiao Wei Sun, ${ }^{*,+}, \S$ and Hilmi Volkan Demir ${ }^{+, \perp, \#}$ \\ ${ }^{\dagger}$ School of Electrical and Electronic Engineering, Nanyang Technological University, Nanyang Avenue, Singapore 639798 \\ ${ }^{\ddagger}$ Institute of Material Research and Engineering, A*STAR (Agency for Science, Technology and Research), 3 Research Link, \\ Singapore 117602 \\ ${ }^{\S}$ Department of Applied Physics, College of Science, Tianjin University, Tianjin 300072, China \\ ${ }^{\perp}$ School of Physical and Mathematical Sciences, Nanyang Technological University, Nanyang Avenue, Singapore 637371 \\ ${ }^{\#}$ Department of Electrical and Electronics Engineering, Department of Physics, UNAM, and National Institute of Materials Science \\ and Nanotechnology, Bilkent University, Bilkent, Ankara, Turkey 06800
}

Supporting Information

ABSTRACT: Tungsten trioxide hydrate $\left(3 \mathrm{WO}_{3} \cdot \mathrm{H}_{2} \mathrm{O}\right)$ films with different morphologies were directly grown on fluorine doped tin oxide (FTO) substrate via a facile crystal-seed-assisted hydrothermal method. Scanning electron microscopy (SEM) analysis showed that $3 \mathrm{WO}_{3} \cdot \mathrm{H}_{2} \mathrm{O}$ thin films composed of platelike, wedgelike, and sheetlike nanostructures could be selectively synthesized by adding $\mathrm{Na}_{2} \mathrm{SO}_{4},\left(\mathrm{NH}_{4}\right)_{2} \mathrm{SO}_{4}$, and $\mathrm{CH}_{3} \mathrm{COONH}_{4}$ as capping agents, respectively. X-ray diffraction (XRD) studies indicated that these films were of orthorhombic structure. The as-prepared thin films after dehydration showed obvious photocatalytic activities. The best film grown using $\mathrm{CH}_{3} \mathrm{COONH}_{4}$ as a capping agent generated anodic
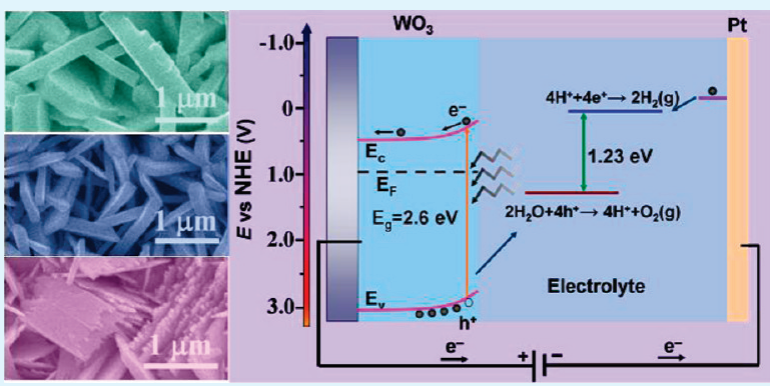
photocurrents of $1.16 \mathrm{~mA} / \mathrm{cm}^{2}$ for oxidization of methanol and $0.5 \mathrm{~mA} / \mathrm{cm}^{2}$ for water splitting with the highest photoconversion efficiency of about $0.3 \%$ under simulated solar illumination.

KEYWORDS: tungsten trioxide, hydrothermal, capping agent, photocatalyst, water splitting

\section{INTRODUCTION}

Assembly of functional nanoscale building blocks in thin film form for example with large surface area and desired morphologies is an important prerequisite for large scale electronic and optoelectronic applications with improved performance. ${ }^{1-3}$ Thin film tungsten trioxide $\left(\mathrm{WO}_{3}\right)$ has attracted great interests due to its wide-ranging applications in a variety of technologies including electrochromic devices, gas sensors, photoelectrochemical devices, and dye-sensitized solar cells. ${ }^{4-9}$ As one of few n-type semiconductors, $\mathrm{WO}_{3}$ has also been considered to be an interesting photocatalytic material, due to its high resistance against photocorrosion, good stability in acidic solution (below ca. $\mathrm{pH} 4$ ) and a suitable band gap for visible light absorption $(\sim 2.6 \mathrm{eV}) .{ }^{8,10}$

Thus far, thin films of $\mathrm{WO}_{3}$ have been grown by various techniques including physical vapor deposition (thermal evaporation and sputtering), ${ }^{11,12}$ and chemical methods (sol-gel and hydrothermal approach). ${ }^{13-17}$ Hydrothermal approach stands out to be a very promising route featuring low reaction temperature, flexible substrate selection and easiness for scaling-up. A number of hydrothermal methods have been used for the preparation of $1 \mathrm{D}$ $\mathrm{WO}_{3}$ nanostructures with various characteristic sizes and morphologies by adding different kinds of inorganic salts or surfactants. ${ }^{18-21}$
Some of the nanostructures with large surface area are assembled into thin film on conductive substrate, showing promising photocatalytic characteristics. For example, Hong investigated the size effect of hydrothermally grown $\mathrm{WO}_{3}$ nanoparticles for photooxidation of water and achieved a maximum photocurrent density of $0.6 \mathrm{~mA} / \mathrm{cm}^{2}$ for the sample calcined at $600{ }^{\circ} \mathrm{C}^{21}$ Although the photocatalytic characteristics of hydrothermally grown $\mathrm{WO}_{3}$ nanostructures have been reported, there have been few works focusing on photocatalytic behavior of hydrothermally grown $\mathrm{WO}_{3}$ films. ${ }^{22}$ Moreover, to directly grow $\mathrm{WO}_{3}$ thin film with controllable morphology and good adhesion on substrates using the hydrothermal methods is much harder to realize.

Herein, we report a simple hydrothermal approach to realize the morphology-controllable synthesis of tungsten oxide hydrate $\left(3 \mathrm{WO}_{3} \cdot \mathrm{H}_{2} \mathrm{O}\right)$ thin film on FTO glasses. Under the assistance of seed layers, $3 \mathrm{WO}_{3} \cdot \mathrm{H}_{2} \mathrm{O}$ thin films composed of platelike, wedgelike, and sheetlike nanostructures could be selectively prepared by adding $\mathrm{Na}_{2} \mathrm{SO}_{4},\left(\mathrm{NH}_{4}\right)_{2} \mathrm{SO}_{4}$, and $\mathrm{CH}_{3} \mathrm{COONH}_{4}$ as capping agents,

Received: September 14, 2010

Accepted: December 8, 2010

Published: January 10, 2011 


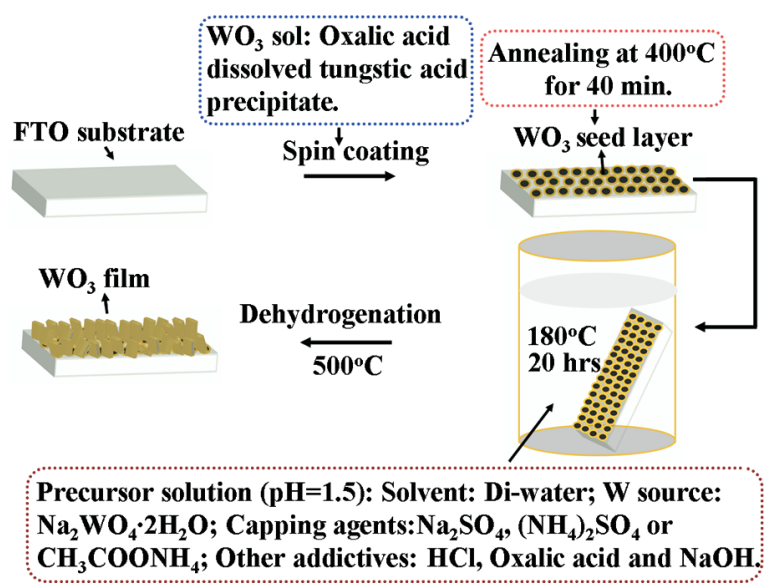

Figure 1. Schematic illustration of the film fabrication process.

respectively. For the purpose of comparison, flowerlike microparticles without seed layers and relatively dense film without addition of any salt were synthesized. The photocatalytic activities of the asprepared thin films for oxidization of methanol and splitting water were also studied.

\section{EXPERIMENTAL SECTION}

2.1. Preparation of Crystal Seeds. One gram of $\mathrm{Na}_{2}$ $\mathrm{WO}_{4} \cdot 2 \mathrm{H}_{2} \mathrm{O}$ was dissolved into $15 \mathrm{~mL}$ of deionized water and then $\mathrm{HCl}$ was added until no more precipitate was formed. The precipitate was washed using deionized water in ice bath for 6 times to obtain $50 \mathrm{~mL}$ of precipitate-containing suspension. Then, $0.9 \mathrm{~g}$ of oxalic acid was added into the suspension under intense stir at $\sim 50{ }^{\circ} \mathrm{C}$. The precipitate was dissolved and the suspension was changed to transparent sol which was used as $\mathrm{WO}_{3}$ seed precursor. The $\mathrm{pH}$ of the above precursor was 1.7.

2.2. Preparation of Substrates. The as-prepared transparent $\mathrm{WO}_{3}$ seed precursor was spun coated onto FTO glasses which were ultrasonic cleaned beforehand by acetone, isopropanol, ethanol, and deionized water in sequence. The spin coating processes were performed at $3000 \mathrm{rpm}$ for $30 \mathrm{~s}$ and repeated for 4 times, during each process the coated substrates were heated at $300^{\circ} \mathrm{C}$ for $\sim 10 \mathrm{~min}$. All the substrates were then heated to $400{ }^{\circ} \mathrm{C}$ in atmosphere for $40 \mathrm{~min}$.

2.3. Preparation of Precursors and Hydrothermal Synthesis. $\mathrm{Na}_{2} \mathrm{WO}_{4} \cdot 2 \mathrm{H}_{2} \mathrm{O}(0.0655 \mathrm{~g})$ was dissolved into $20 \mathrm{~mL}$ of deionized water and then $\sim 4 \mathrm{~mL}$ of $\mathrm{HCl}$ was added into the solution until no more precipitate was formed. The above suspension was kept in an ice bath for $10 \mathrm{~min}$ and then the upper liquid was removed. Deionized water was added into it to obtain a final $20 \mathrm{~mL}$ suspension. Then $0.14 \mathrm{~g}$ of oxalic acid was added into the above suspension under intensely stir at $\sim 50{ }^{\circ} \mathrm{C}$. After the solution was stirred for $5 \mathrm{~min}, 0.04 \mathrm{~g}$ of capping agent $\mathrm{Na}_{2} \mathrm{SO}_{4}$ was added. For the cases using other capping agents, $0.04 \mathrm{~g}$ of $\left(\mathrm{NH}_{4}\right)_{2} \mathrm{SO}_{4}$ or $0.1 \mathrm{~g}$ of $\mathrm{CH}_{3} \mathrm{COONH}_{4}$ was added, accordingly. Then $1 \mathrm{M} \mathrm{NaOH}$ solution was slowly added into the above solution with stirring until the $\mathrm{pH}$ value of the solution reached 1.5. For the purpose of comparison, a solution without any capping agent was also prepared. The as-prepared solutions were transferred into autoclaves as precursors for hydrothermal growth. The FTO glasses coated by $\mathrm{WO}_{3}$ seed layers were put into autoclaves and the reaction were kept at $180^{\circ} \mathrm{C}$ for $20 \mathrm{~h}$. For comparison, bare FTO glass (without crystal seeds) was also used as a reference substrate. The as-prepared thin films were washed using deionized water. To test their photocatalytic activities for oxidization of methanol and water, the asprepared thin films were calcined in air at $500{ }^{\circ} \mathrm{C}$ for $30 \mathrm{~min}$. The experimental process is schematically illustrated in Figure 1.

2.4. Characterizations. The crystal structure of the products was identified by X-ray powder diffraction (XRD, Siemens) using $\mathrm{Cu} \mathrm{K \alpha _{1 }}$

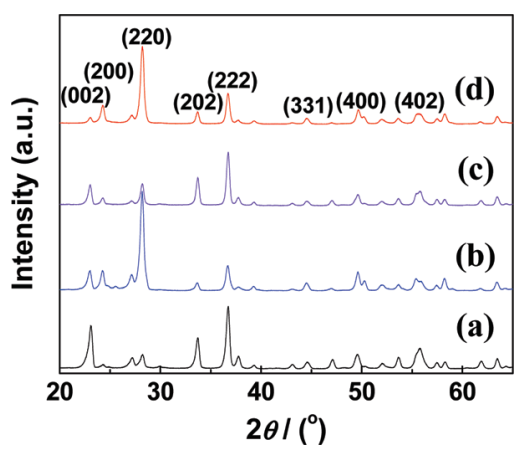

Figure 2. XRD patterns of the as-synthesized thin films prepared (a) without any salt added, (b) with $\mathrm{Na}_{2} \mathrm{SO}_{4}$, (c) with $\left(\mathrm{NH}_{4}\right)_{2} \mathrm{SO}_{4}$, and (d) with $\mathrm{CH}_{3} \mathrm{COONH}_{4}$ added.

$(\lambda=0.15406 \mathrm{~nm})$ radiation. The morphologies of the as-prepared thin films were observed by scanning electron microscopy (SEM, JSM 5910LV). High-resolution transmission electron microscopy (HRTEM) images were obtained by a JEM-2010 microscope using an accelerating voltage of $200 \mathrm{kV}$. The UV-vis absorption spectra were measured using a UV-vis spectrophotometer (Lambda 950). Photocatalytic activity was measured in a typical three-electrode configuration in $1 \mathrm{M} \mathrm{H}_{2} \mathrm{SO}_{4}$ and $1 \mathrm{M} \mathrm{H}_{2} \mathrm{SO}_{4}$ containing $0.1 \mathrm{M}$ methanol as electrolyte, respectively. $\mathrm{Ag} / \mathrm{AgCl}$ was used as reference electrode and a Pt foil as counter electrode. A $200 \mathrm{~W}$ xenon lamp (Oriel, $66011)$ with a filter $(>300 \mathrm{~nm})$ was placed near the photoelectrode to simulate solar irradiation (the light intensity was adjusted to $100 \mathrm{~mW} / \mathrm{cm}^{2}$ ). The photocurrent measurements were conducted using a computer controlled potentiostat (VersaSTAT 3F Potentiostat/Galvanostat, Princeton Applied Research).

\section{RESULTS AND DISCUSSION}

Figure 2 shows the XRD patterns of the as-synthesized films grown without and with addition of different capping agents. Intense and sharp diffraction peaks are observed, indicative of a high degree of crystallinity. The diffraction peaks of the as-prepared films appear at the same positions. It is also observed that there are no other impurity phase peaks. All the peaks can be indexed to the orthorhombic phase of $3 \mathrm{WO}_{3} \cdot \mathrm{H}_{2} \mathrm{O}$ (JCPDF 87-1203) with constants of $a=7.345, b=$ 12.547, and $c=7.737 \AA$. Moreover, the full width at half-maximum of the (222) crystal planes of all orthorhombic $3 \mathrm{WO}_{3} \cdot \mathrm{H}_{2} \mathrm{O}$ patterns can be used to estimate the average crystalline size of the $3 \mathrm{WO}_{3}$. $\mathrm{H}_{2} \mathrm{O}$, using the Debye - Scherrer equation

$$
D=K \lambda /(\beta \cos \theta)
$$

where $D$ is the average crystalline size, $\beta$ is the corrected band broadening (full width at half-maximum), $K$ is a constant taken as 0.89 here, $\lambda$ is the wavelength of the X-ray radiation $\left(\mathrm{Cu} \mathrm{K \alpha} \alpha_{1}=\right.$ $0.15406 \mathrm{~nm}$ ), and $\theta$ is the diffraction angle. The average crystalline size for nanostructures of $3 \mathrm{WO}_{3} \cdot \mathrm{H}_{2} \mathrm{O}$ films synthesized without capping salt is estimated at $24.0 \mathrm{~nm}$. The sizes of nanostructures for adding $\mathrm{Na}_{2} \mathrm{SO}_{4},\left(\mathrm{NH}_{4}\right)_{2} \mathrm{SO}_{4}$, and $\mathrm{CH}_{3} \mathrm{COONH}_{4}$ are 21.4, 27.3, and $24.5 \mathrm{~nm}$, respectively. However, the diffraction patterns of these films show some differences in the intensities. The films grown with $\mathrm{Na}_{2} \mathrm{SO}_{4}$ or $\mathrm{CH}_{3} \mathrm{COONH}_{4}$ show a highest peak intensity of (220), suggesting that most of the (220) planes are parallel to the substrate. ${ }^{22}$ In the patterns of the films grown without salt or with $\left(\mathrm{NH}_{4}\right)_{2} \mathrm{SO}_{4}$, a peak attributable to the (222) diffraction exhibits high intensity, indicating selective orientation of (222) planes parallel to the substrate. The various selective orientations can be attributed to the different capping effect of salts in the condensation and polymerization of $\mathrm{WO}_{6}$ octahedral clusters. 


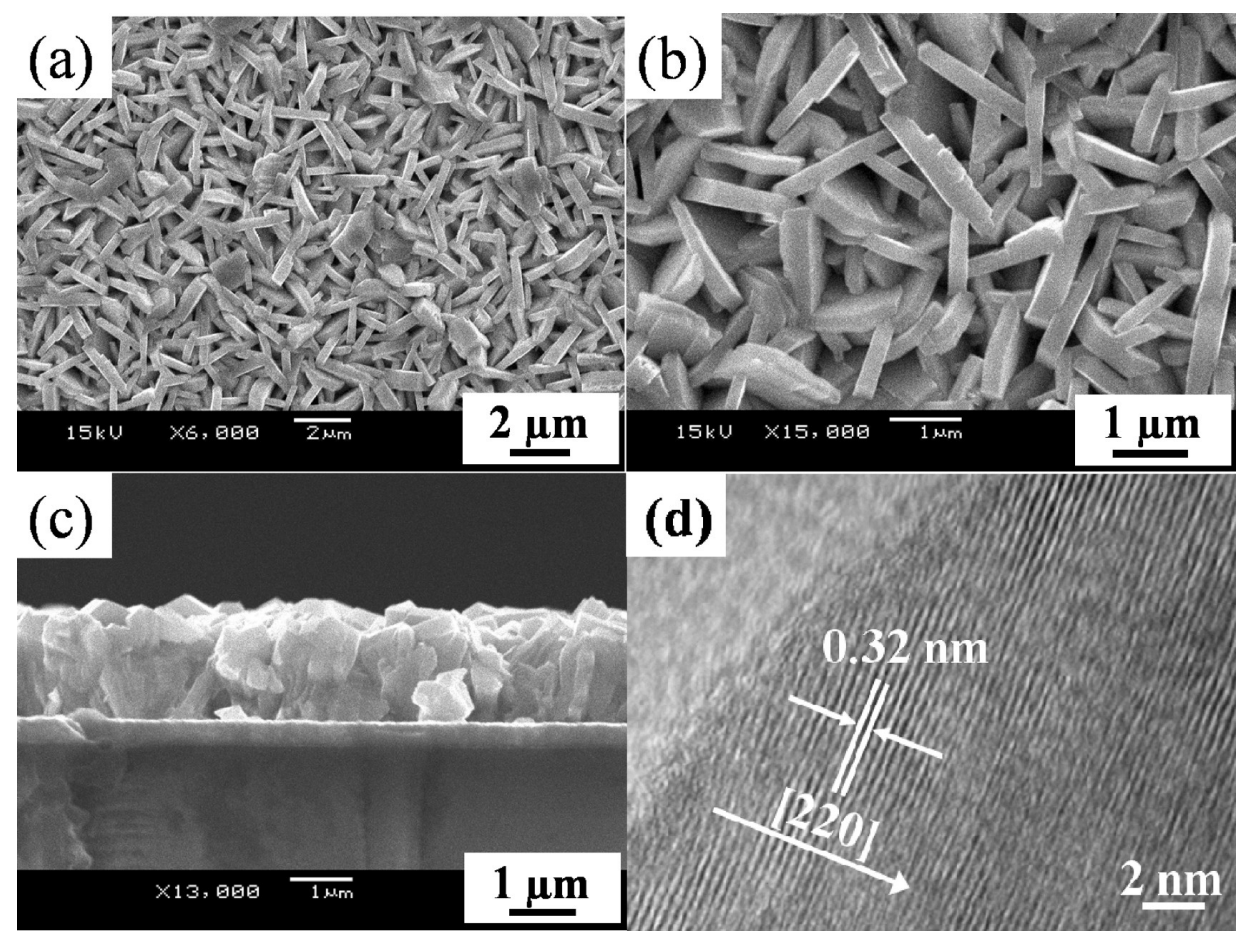

Figure 3. (a) SEM image of as-synthesized tungsten oxide hydrate film composed of plate-like nanostructures with $\mathrm{Na}_{2} \mathrm{SO}_{4}$ as capping agent, (b) higher-magnification SEM image (top view), (c) cross-sectional image of the film, and (d) HRTEM image of a single nanoplate.

According to previous reports, ${ }^{19} 1 \mathrm{D} \mathrm{WO}_{3}$ nanostructures could be controllably synthesized by addition of sulfate as the capping agent by a hydrothermal approach. Inspired by these results, morphology-controllable synthesis of $\mathrm{WO}_{3}$ film may be realized by adding sulfate or other capping agents into the precursor to direct the nanostructures' growth. Hence $\mathrm{Na}_{2} \mathrm{SO}_{4}$ was introduced in our synthesis. Morphologies of the as-synthesized film are shown in Figure 3. It can be seen that a film consisting of platelike nanostructure is assembled on the surface of FTO (Figure 3a and b). These nanoplates with clear crystal facets gathered together and a lot of pores were formed among these accumulated nanoplates, leading to a coarse surface. Crosssectional image of the film (Figure 3c) shows its thickness is about $2 \mu \mathrm{m}$, and the as-synthesized film has a good adhesion to the substrate. Figure 3d shows the HRTEM image of a single nanoplate. Clear lattice fringes corresponding to the (220) plane with $d$-spacing of $0.32 \mathrm{~nm}$ can be seen, indicating single-crystal quality of the $3 \mathrm{WO}_{3} \cdot \mathrm{H}_{2} \mathrm{O}$ nanoplate, which is in good agreement with the $\mathrm{XRD}$ result (Figure 2).

To investigate the influence of the seed layer on the morphology of as-synthesized film, bare FTO substrate without any seed layer was compared. It can be seen that flower-like particles spreading on the surface of FTO with diameter of $\sim 8-10 \mu \mathrm{m}$ and height of $\sim 2-4 \mu \mathrm{m}$ were synthesized (Figure $4 \mathrm{a}, \mathrm{b}$ ). Some particles are not completely developed which may due to the randomness of self-assembly process. The higher-magnification image of a single particle (Figure $4 \mathrm{~b}$ ) shows that the center of particle is made up of lamina layers and many small nanoplates grow along the center. From this result, we can get a conclusion that the seed layer does play a key role in assembling the $3 \mathrm{WO}_{3} \cdot \mathrm{H}_{2} \mathrm{O}$ thin film and offers the nucleation and growing sites for the film. These flower-like particles can be easily removed from the substrate. However, the film grown with seed layers shows good adhesion to the substrate, which further verifies the crucial impact of seed layer on assembling of the $3 \mathrm{WO}_{3} \cdot \mathrm{H}_{2} \mathrm{O}$ film.

For comparison, precursor solution without any salt (with seed layer and other conditions remain the same as in Figure 3) was compared as well. It can be seen from images $c$ and $d$ in Figure 4that dense thin film made up of irregular particles with different sizes was prepared, which is quite different from those films grew using capping salts. Hence, the morphologies of nanostructures are determined by the capping agents, similar to the hydrothermally grown $1 \mathrm{D} \mathrm{WO}_{3}$ nanostructures grown with capping agent. ${ }^{15,18,19}$

To further investigate the influence of cations on the morphology of the as-synthesized thin film, we added $\left(\mathrm{NH}_{4}\right)_{2} \mathrm{SO}_{4}$ into the precursor instead of $\mathrm{Na}_{2} \mathrm{SO}_{4}$. Figure 5 a show the top-view images of the resultant film. It can be seen that a film composed of uniform wedgelike nanostructures was synthesized. These wedgelike nanostructures with size of $\sim 2 \mu$ m gathered together and a lot of pores can be obviously observed among them. These pores are formed due to the accumulation of the nanowedges. It is obvious that the obtained nanostructures grown with $\left(\mathrm{NH}_{4}\right)_{2} \mathrm{SO}_{4}$ have sharp edges and smaller characteristic size compared with the nanostructures grown with $\mathrm{Na}_{2} \mathrm{SO}_{4}$. The cross-sectional image (inset of Figure 5a) shows that the thickness of the as prepared film is $\sim 2 \mu \mathrm{m}$. The HRTEM image of the edge of a single "wedge" in Figure $5 \mathrm{~b}$ shows its crystal lattices of $0.38 \mathrm{~nm}$ corresponding to the $d$-spacing of (002) planes. Clear lattice fringes indicate its singlecrystal quality. The inset of Figure $5 b$ depicts the SAED image of the single "wedge". Regular diffraction spots also prove the wedge is single-crystalline.

The above result indicates that besides sodium ions, ammonium ions also has some effect in directing the crystal growth of $3 \mathrm{WO}_{3} \cdot \mathrm{H}_{2} \mathrm{O}$ nanostructures and determining the final morphologies of the as-synthesized films. Up to now, controllable synthesis of $\mathrm{WO}_{3}$ nanostructures has been achieved by adding 


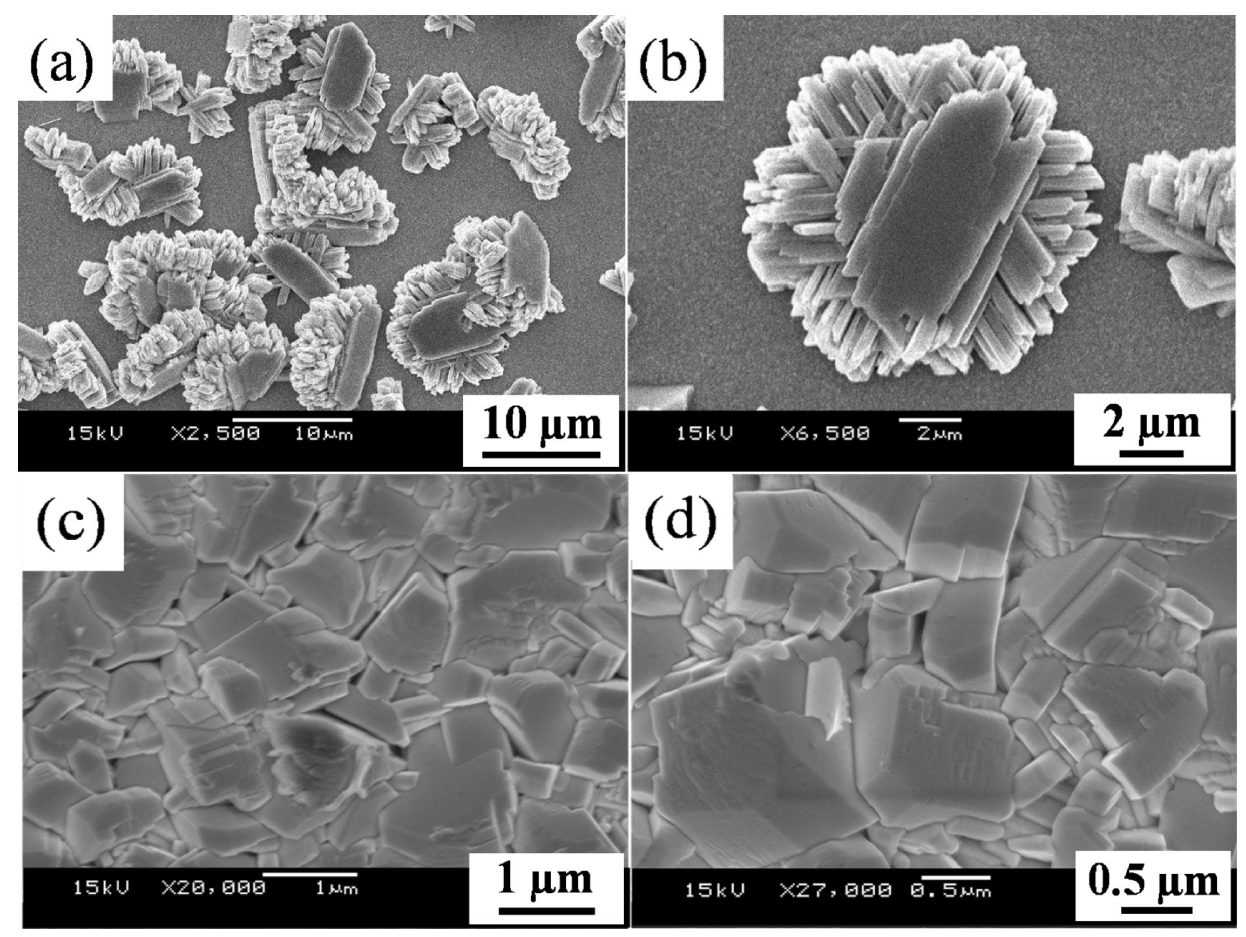

Figure 4. (a, b) SEM images of as-synthesized flowerlike tungsten oxide hydrate particles without seed layer, (c, d) as-synthesized tungsten oxide hydrate thin film grown without any salt.
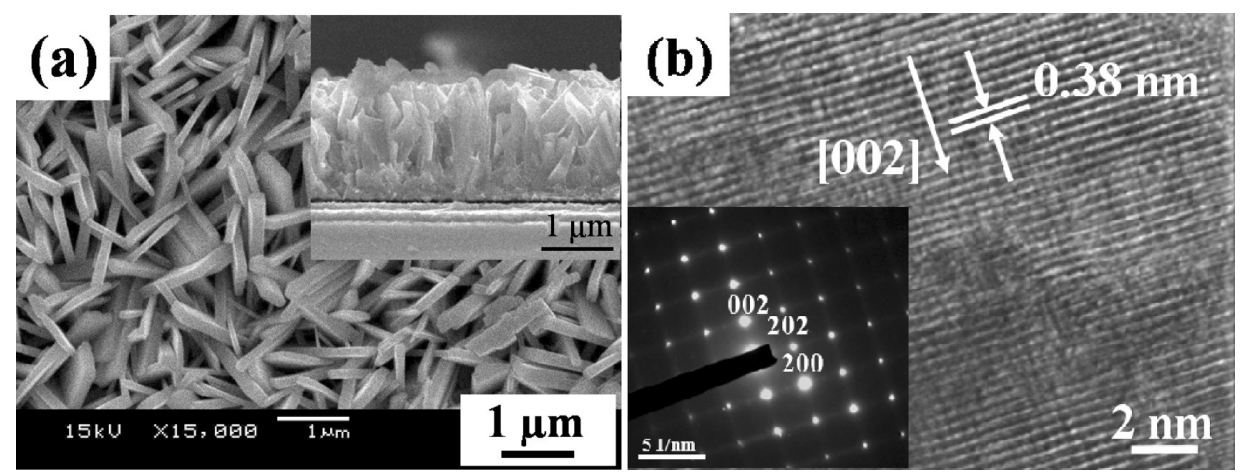

Figure 5. (a) SEM image of as-synthesized tungsten oxide hydrate film composed of wedge-like nanostructures grown with $\left(\mathrm{NH}_{4}\right)_{2} \mathrm{SO}_{4}$ as capping agent. The inset shows a cross-sectional image of the film. (b) HRTEM image of a single nanowedge. The inset of $b$ shows the SAED pattern from a nanowedge.

various salts as capping agents, such as $\mathrm{RbSO}_{4}, \mathrm{Na}_{2} \mathrm{SO}_{4},\left(\mathrm{NH}_{4}\right)_{2^{-}}$ $\mathrm{SO}_{4}$ and $\mathrm{NaCl}^{15,18}$ However, to the best of our knowledge, acetate is rarely reported. As acetate has been widely used for $\mathrm{ZnO}$ nanostructure synthesis, ${ }^{23}$ we studied the influence of $\mathrm{CH}_{3} \mathrm{CO}$ $\mathrm{ONH}_{4}$ as a capping agent on the as-synthesized film. SEM images of the as-obtained film are shown in images $a$ and $b$ in Figure 6. It can be seen that the thin film consists of sheet-like nanostructures. The "nanosheet" with a thickness of $\sim 50 \mathrm{~nm}$ grew disorderly on the substrate, forming a quite rough surface. It can be further seen from the higher magnification (Figure 6b) that some edges of the nanosheets are not smooth, showing a zigzag shape. Numerous pores are existed among these nanosheets. These nanostructures should be more beneficial for accelerating the interface electron kinetics between the sheet and electrolyte for its larger active surface area. Figure $6 \mathrm{c}$ shows the TEM image of a nanosheet and its ragged edge can be clearly discerned. The inset of Figure $6 \mathrm{c}$ shows the SAED pattern of the nanosheet and its single-crystal quality could be proved by the regular diffraction spots. Clear lattice fringes correspond to the $d$-spacing of (002) planes with lattice spacing of $0.38 \mathrm{~nm}$, which was taken from the corner area of the nanosheet (the inset of Figure 6d) are shown in Figure 6d, further indicating its single-crystal quality, which is in good agreement with Figure $6 \mathrm{c}$. The above results indicate that acetate do have a capping effect on the crystal growth of $3 \mathrm{WO}_{3}$. $\mathrm{H}_{2} \mathrm{O}$ nanostructures. Moreover, it can be seen that the HRTEM image and SAED pattern of the selected area from the film grown with $\mathrm{CH}_{3} \mathrm{COONH}_{4}$ is quite similar to that grown with $\left(\mathrm{NH}_{4}\right)_{2}-$ $\mathrm{SO}_{4}$ due to their same crystalline structure (orthorhombic phase of $3 \mathrm{WO}_{3} \cdot \mathrm{H}_{2} \mathrm{O}$ ). And the similar HRTEM images and SAED patterns imply that the as-synthesized nanostructures with $\left(\mathrm{NH}_{4}\right)_{2}$ $\mathrm{SO}_{4}$ and $\mathrm{CH}_{3} \mathrm{COONH}_{4}$ may have the same growth direction. However, it can be seen that the morphologies, sizes, and thickness of the nanostructures synthesized using different salts are different (Figure 5 and 6); moreover, the arrangement of these different nanostructures in the grown films are also different. These factors significantly affect the intensities of diffraction peaks of the films 


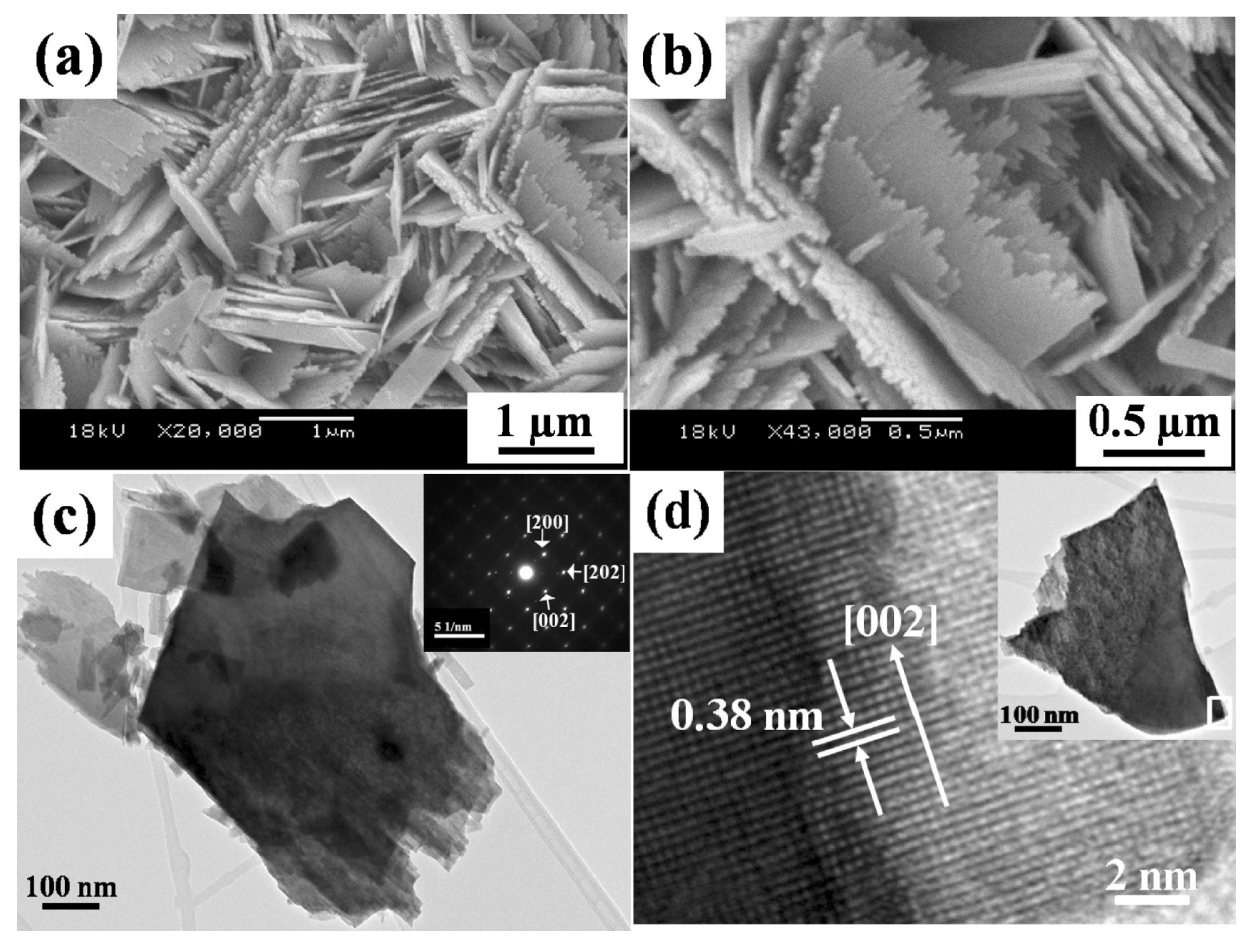

Figure 6. (a) SEM image of as-synthesized tungsten oxide hydrate film with sheet-like nanostructures grown with $\mathrm{CH}_{3} \mathrm{COONH}_{4}$ as capping agent and (b) HRTEM images of a single nanosheet. The inset of Figure (b) shows the SAED pattern from a nanosheet.

grown using different salts, which is why Figure 2 shows different XRD diffraction intensities of the films.

Tungstate ions exhibit a lot of species in an aqueous solution at different $\mathrm{pH}$ values, such as $\mathrm{WO}_{4}{ }^{2-}, \mathrm{HWO}_{4}{ }^{-}, \mathrm{H}_{2} \mathrm{WO}_{4}, \mathrm{HW}_{6} \mathrm{O}_{21}{ }^{-}$, and $\mathrm{W}_{6} \mathrm{O}_{21}{ }^{6-}{ }^{24}$ The major species is $\mathrm{WO}_{4}{ }^{2-}$ with $\mathrm{pH}>7$. The dropping of concentrated $\mathrm{HCl}(37 \%)$ will force the $\mathrm{WO}_{4}{ }^{2-}$ to precipitate from solution and $\mathrm{H}_{2} \mathrm{WO}_{4}$ will be formed, as shown in the reaction. ${ }^{2}$

$$
\mathrm{WO}_{4}{ }^{2-}+2 \mathrm{H}^{+} \rightarrow \mathrm{H}_{2} \mathrm{WO}_{4}
$$

With the increase in $\mathrm{H}^{+}$concentration, the intermediate $\mathrm{H}_{2} \mathrm{WO}_{4}$ shows high condensation polymerization tendency where two hydroxyl ligands combine to eliminate water and form a shared oxygen bond between the two tungsten centers. Further addition of acid will result in the formation of dihydroxy ligands $\mathrm{W}-(\mathrm{OH})_{2}$ by progressively hydrated tungsten oxo ligands $(\mathrm{W}=\mathrm{O})$. After further condensation and increase in the cross-linking degree of these ligands, a final three-dimensional octahedral $\mathrm{WO}_{6}$ structure in which tungsten centers are cross-linked to adjacent tungsten centers via four or six shared oxygen bonds, forming structures similar to those found in polyoxo-tungstates. ${ }^{17,25,26}$ Then the oxalic acid is added into the complex coordination system and a transparent colloidal is obtained. It is believed that the oxalic acid will tailor the long coordination complex through hydroxyl groups, since the colloidal particle size is largely dependent on the concentration of oxalic acid. $^{27}$ Finally, induced by various salts, these short coordinated clusters undergo further condensation and polymerization by hydrothermal reactions under elevated temperature and high pressure, forming platelike, wedgelike, and sheetlike nanostructures on the surface of seed-layer-coated substrate. The seeds coated on substrate act as nucleation and growth sites. The whole process in detail is schematically illustrated in the Supporting Information, Figure S4.

$\mathrm{WO}_{3}$ is an n-type semiconductor with a band gap $\sim 2.6 \mathrm{eV}$, which can utilize $\sim 12 \%$ of solar spectrum. ${ }^{28}$ Moreover, it shows a high stability in acid bath. These advantages make it a promising candidate in photocatalytic degradation of organic compounds and water splitting to produce hydrogen. ${ }^{7,8,29}$ To investigate their photocatalytic performances, all the films were calcined in atomosphere at $500{ }^{\circ} \mathrm{C}$ for $30 \mathrm{~min}$. As previously reported, ${ }^{13}$ $\mathrm{WO}_{3}$ film prepared by a sol-gel method shows the highest photocatalytic activity after being calcined at $500{ }^{\circ} \mathrm{C}$. The crystal structure evolution as a function of temperature is also investigated on the film synthesized with $\mathrm{Na}_{2} \mathrm{SO}_{4}$ as capping agent. It can be seen from Figure 7 that there is no obvious differences in the diffraction pattern of as-prepared film for a calcination temperature up to $300{ }^{\circ} \mathrm{C}$. Because of the dehydration, some peaks' relative intensities get changed. After calcination at $400{ }^{\circ} \mathrm{C}$, the XRD pattern gets obviously changed, showing some characteristic diffraction peaks of monoclinic $\mathrm{WO}_{3}$ (PDF 24-0747). It is believed that this is a mixture of both orthorhombic and monoclinic structure. For calcination temperature of $500{ }^{\circ} \mathrm{C}$, the structure changes to monoclinic $\mathrm{WO}_{3}$ (JCPDF 24-0747) with lattice constants of $a=7.297 \AA, b=7.539 \AA$, and $c=7.688 \AA$ (see the Supporting Information, Figure S3). Our experiment results show that the other two films prepared using $\left(\mathrm{NH}_{4}\right)_{2} \mathrm{SO}_{4}$ and $\mathrm{CH}_{3} \mathrm{COONH}_{4}$ as capping agents follow the same crystal structure change after calcination.

Figure 8 shows the UV-vis absorption spectra of the films after calcination. It can be seen that all the films show high UV light absorption. Moreover, the absorption band edge for films prepared with $\mathrm{CH}_{3} \mathrm{COONH}_{4},\left(\mathrm{NH}_{4}\right)_{2} \mathrm{SO}_{4}$ and $\mathrm{Na}_{2} \mathrm{SO}_{4}$ as capping agents show obviously red shifts. The broadened light absorption is much desired for photocatalytic applications, because more photo excited electrons will be generated contributing a higher photocatalytic efficiency.

To investigate the photocatalytic properties of as-prepared films, the photocurrent densities were measured in a $1 \mathrm{M} \mathrm{H}_{2} \mathrm{SO}_{4}$ solution containing $0.1 \mathrm{M}$ methanol under illumination $\left(100 \mathrm{~mW} / \mathrm{cm}^{2}\right)$ 


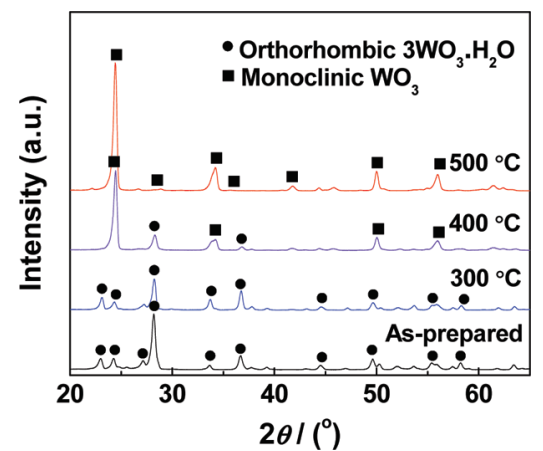

Figure 7. $\mathrm{XRD}$ patterns of the as-synthesized thin films with $\mathrm{Na}_{2} \mathrm{SO}_{4}$ as the capping agent. (a) The as-prepared tungsten oxide hydrate thin film, after annealing at (b) 300, (c) 400 and (d) $500{ }^{\circ} \mathrm{C}$ for $30 \mathrm{~min}$, respectively.

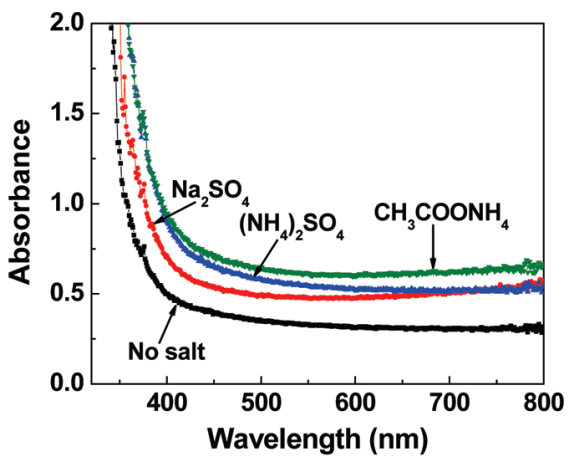

Figure 8. The UV-vis absorption spectra of the as-synthesized films grown (a) without any salt, with $\mathrm{Na}_{2} \mathrm{SO}_{4}$ (b), (c) $\left(\mathrm{NH}_{4}\right)_{2} \mathrm{SO}_{4}$ and (d) $\mathrm{CH}_{3} \mathrm{COONH}_{4}$ as capping agents, respectively.

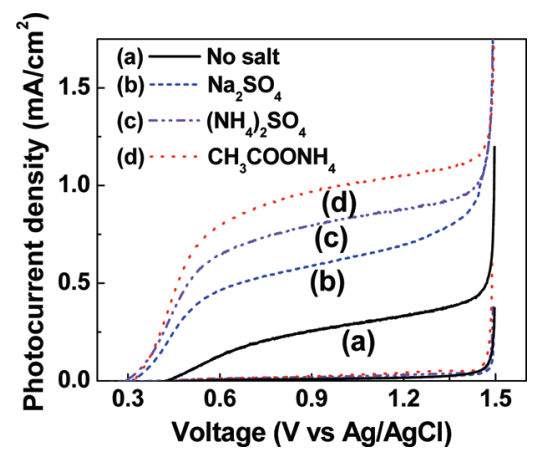

Figure 9. Current-potential scans of as-synthesized films measured in darkness and under simulated solar spectrum in a $1 \mathrm{M} \mathrm{H}_{2} \mathrm{SO}_{4}$ solution containing $0.1 \mathrm{M}$ methanol.

(Figure 9). It can be seen that the current densities in dark are small (typically $<100 \mu \mathrm{A} / \mathrm{cm}^{2}$ ) for all calcined films in the effective range of applied potentials. Compared to the film synthesized without capping agent $\left(0.40 \mathrm{~mA} / \mathrm{cm}^{2}\right)$, the photocurrent densities of the films with $\mathrm{Na}_{2} \mathrm{SO}_{4},\left(\mathrm{NH}_{4}\right)_{2} \mathrm{SO}_{4}$, and $\mathrm{CH}_{3} \mathrm{COONH}_{4}$ capping agents show an obviously increase of 112,140 , and $180 \%$ to $0.85,0.96$, and $1.12 \mathrm{~mA} / \mathrm{cm}^{2}$ at $1.4 \mathrm{~V}$ vs $\mathrm{Ag} / \mathrm{AgCl}$, respectively. The photocatalytic performances of the films are in good agreement with the optical absorption. Moreover, the open-circuit voltages $\left(V_{\mathrm{OCV}}\right)$ are negatively shifted from $0.42 \mathrm{~V}$ of the one without salt to $0.31,0.29$, and $0.32 \mathrm{~V}$ for $\mathrm{WO}_{3}$ films obtained with $\mathrm{Na}_{2} \mathrm{SO}_{4},\left(\mathrm{NH}_{4}\right)_{2} \mathrm{SO}_{4}$, and $\mathrm{CH}_{3} \mathrm{COONH}_{4}$ capping agents, respectively, which are attributed to
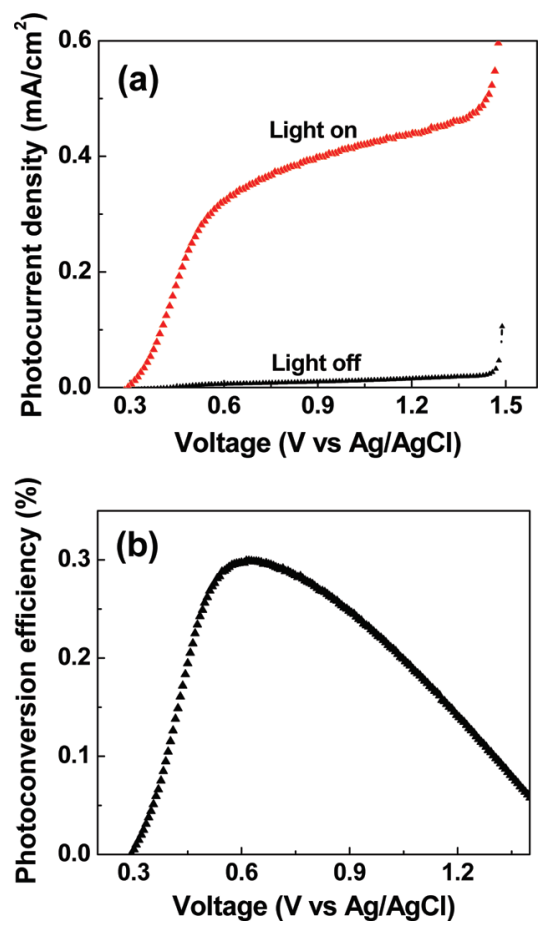

Figure 10. (a) Current-potential scans of films grown with $\mathrm{CH}_{3} \mathrm{COONH}_{4}$ as capping agent measured in darkness and under simulated solar spectrum in a $1 \mathrm{M} \mathrm{H}_{2} \mathrm{SO}_{4}$ solution and (b) photoconversion efficiency.

the numerous pores existing among the nanostructures assembled in films that could increase the interface between the photoanode and electrolyte, facilitating the hole transfer to methanol more efficiently. The $\mathrm{WO}_{3}$ nanostructures absorb effective photons that caused the generation of valence band holes $\left(\mathrm{h}_{\mathrm{vb}}{ }^{+}\right)$and conduction band electrons $\left(\mathrm{e}_{\mathrm{cb}}{ }^{-}\right)$. These photon-generated holes serve as oxidation sites for the absorbed methanol molecules, i.e.

$$
\begin{gathered}
\mathrm{WO}_{3} \stackrel{h v}{\rightarrow} \mathrm{WO}_{3}\left(\mathrm{~h}_{\mathrm{vb}}{ }^{+}, \mathrm{e}_{\mathrm{cb}}{ }^{-}\right) \\
\mathrm{CH}_{3} \mathrm{OH}+2 \mathrm{~h}^{+} \rightarrow \mathrm{CO}+2 \mathrm{H}^{+}+\mathrm{H}_{2} \\
2 \mathrm{H}^{+}+2 \mathrm{e}^{-} \rightarrow \mathrm{H}_{2}
\end{gathered}
$$

The best film prepared with $\mathrm{CH}_{3} \mathrm{COONH}_{4}$ renders the highest photocurrent density of about $1.16 \mathrm{~mA} / \mathrm{cm}^{2}$ (at $1.45 \mathrm{~V}$ ). However, this value is smaller compared to the reported porous sol- gel $\mathrm{WO}_{3}$ films $\left(4.1 \mathrm{~mA} / \mathrm{cm}^{2}\right.$, AM 1.5, film thickness $\left.2.8 \mu \mathrm{m}\right) .{ }^{14}$ The inferior catalytic performance for photodegradation of methanol may be due to the less optimum film thicknesses and slow carrier transporting kinetics. Further study is required to optimize the parameters.

The photoelectrochemical performance of film synthesized with $\mathrm{CH}_{3} \mathrm{COONH}_{4}$ capping agent for hydrogen production through water splitting was also investigated in $1 \mathrm{M} \mathrm{H}_{2} \mathrm{SO}_{4}$ and shown in Figure 10a. The highest photocurrent density of about $0.5 \mathrm{~mA} / \mathrm{cm}^{2}$ can be obtained under illumination, which is comparable to other reported values. ${ }^{21,30}$ The photoconversion efficiency (PCE) of light to hydrogen energy is calculated according to the following eq ${ }^{31}$

$$
\operatorname{PCE}(\%)=\left[J_{\mathrm{p}}\left(E_{\mathrm{WS}}-\left|E_{\mathrm{app}}\right|\right) / I_{\mathrm{o}}\right] \times 100
$$

where $J_{\mathrm{p}}$ is the photocurrent density $\left(\mathrm{mA} / \mathrm{cm}^{2}\right), I_{\mathrm{o}}$ is the incident light intensity $\left(100 \mathrm{~mW} / \mathrm{cm}^{2}\right), E_{\mathrm{WS}}$ is the standard reversible 


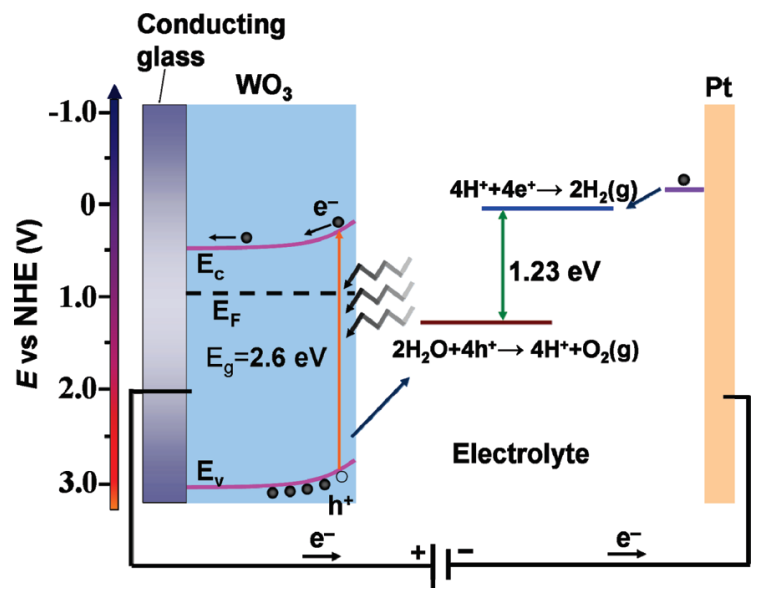

Figure 11. Schematic of the band diagram of $\mathrm{WO}_{3}$ photoanode and operation of the photoelectrochemical cell. The electrolyte is $1 \mathrm{M}$ $\mathrm{H}_{2} \mathrm{SO}_{4}$ solution.

potential for water splitting reaction $(1.23 \mathrm{~V}$ for the watersplitting reaction at $\mathrm{pH} 0)$, and $\left|E_{\text {app }}\right|$ refers to the absolute value of the applied potential $E_{\text {app }}$, which is obtained as

$$
E_{\text {app }}=\left(E_{\text {meas }}-E_{\text {ocp }}\right)
$$

where $E_{\text {meas }}$ is the electrode potential at which the photocurrent density $J_{\mathrm{p}}$ is measured, and $E_{\mathrm{ocp}}$ is the electrode potential at open circuit condition under the same illumination intensity. It can be seen from Figure $10 \mathrm{~b}$ that a highest PCE value of about $0.3 \%$ is obtained at $0.65 \mathrm{~V}$ bias for our experiment. More work is underway to improve the photoconversition efficiency by optimizing the electrolyte, film thickness and annealing conditions.

The band diagram of the $\mathrm{WO}_{3}$ photoanode and operation of the photoelectrochemical cell was schematically shown in Figure 11. When the $\mathrm{WO}_{3}$ photoanode is placed in contact with the electrolyte, a depletion layer at the interface will be formed resulting from the move of electrons from $\mathrm{WO}_{3}$ to electrolyte, producing an upward bending of the band. ${ }^{32}$ Upon illumination, photogenerated electrons will be excited and injected into the conduction band, leaving the holes in the valence band. An external bias is required to pump the electrons to the cathode and elevate the cathode $(\mathrm{Pt})$ Fermi level $\mathrm{E}_{\mathrm{F}}$ above the $\mathrm{H}^{+} / \mathrm{H}_{2}$ energy level, thus making the process of water decomposition possible. ${ }^{33}$ The hydrogen ions will be reduced by electrons, and hydrogen will be formed at the side of Pt. At the same time, the holes in the valence band will transfer to the electrolyte to oxidize water and oxygen will be generated on the surface of $\mathrm{WO}_{3}$. The efficiency of the cell could be further improved by preciously tailoring the $\mathrm{WO}_{3}$ nanostructures and increasing its surface area.

\section{CONCLUSIONS}

We report a hydrothermal approach to directly grow porous tungsten trioxide hydrate $\left(3 \mathrm{WO}_{3} \cdot \mathrm{H}_{2} \mathrm{O}\right)$ thin films with different morphologies on transparent conductive glasses in a large scale. Systematic investigations of the influence of seed layer and different capping agents on the morphologies and structures of the as-synthesized films have been carried out. It was found that flower-like particles with sizes of $\sim 8-10 \mu \mathrm{m}$ were synthesized and spread on the substrate without seed layers. Under the assistance of seed layer, dense thin film was formed without capping agent. After adding suitable amount of $\mathrm{CH}_{3} \mathrm{COONH}_{4}$,
$\left(\mathrm{NH}_{4}\right)_{2} \mathrm{SO}_{4}$ and $\mathrm{Na}_{2} \mathrm{SO}_{4}$ into the precusor, thin films consisted of sheetlike, wedgelike, and platelike nanostructures could be synthesized, respectively. The dehydrated porous films showed high photocatalytic activities for photodegradation of methanol. The film grown using $\mathrm{CH}_{3} \mathrm{COONH}_{4}$ as the capping agent could generate anodic photocurrents of $1.15 \mathrm{~mA} / \mathrm{cm}^{2}$ for oxidization of methanol and $0.5 \mathrm{~mA} / \mathrm{cm}^{2}$ for water splitting, the highest photoconversion efficiency of about $0.3 \%$ can be obtained for water splitting under simulated solar illumination.

\section{ASSOCIATED CONTENT}

S Supporting Information. Additional figures, XRD patterns, and schematic (PDF). This material is available free of charge via the Internet at http://pubs.acs.org/.

\section{AUTHOR INFORMATION}

\section{Corresponding Author}

*E-mail: exwsun@ntu.edu.sg. Tel: +65-67905369. Fax: +6567933318.

\section{ACKNOWLEDGMENT}

We thank he Science and Engineering Research Council Public Sector Fund from Agency for Science, Technology and Research (A*STAR) of Singapore (Grant No. 092101 0057), Academic Research Fund from the Ministry of Education of Singapore (Grant No. RGM44/06), and the National Research Foundation Research Fellowship program (NRF-2009-RF-09) of Singapore for support. The work is also supported by National Natural Science Foundation of China (NSFC) (Projects 61006037 and 61076015).

\section{REFERENCES}

(1) Wang, J. X.; Sun, X. W.; Yang, Y.; Huang, H.; Lee, Y. C.; Tan, O. K.; Vayssieres, L. Nanotechnology 2006, 17, 4995.

(2) Vayssieres, L.; Graetzel, M. Angew. Chem., Int. Ed. 2004, 43, 3666.

(3) Sadek, A. Z.; Zheng, H. D.; Latham, K.; Wilodarski, W.; Kalantarzadeh, K. Langmuir 2009, 25, 509.

(4) Granqvist, C. G. Sol. Energy Mater. Sol. Cells 2000, 60, 201.

(5) Niklasson, G. A.; Granquist, C. G. J. Mater. Chem. 2007, 17, 127.

(6) Li, X. L.; Lou, T. J.; Sun, X. M.; Li, Y. D. Inorg. Chem. 2004, 43, 5442

(7) Alexander, B. D.; Kulesza, P. J.; Rutkowska, I.; Solarska, R.; Augustynski, J. J. Mater. Chem 2008, 18, 2298.

(8) Santato, C.; Ulmann, M.; Augustynski, J. J. Phys. Chem. B 2001, 105, 936.

(9) Cheng, P.; Deng, C. S.; Dai, X. M.; Li, B.; Liu, D. N.; Xu, J. M. J. Photochem. Photobiol., A 2008, 195, 144.

(10) Butler, M. A. J. Appl. Phys. 1977, 48, 1914.

(11) Sun, H. T.; Cantalini, C.; Lozzi, L.; Passacantando, M.; Santucci, S.; Pelino, M. Thin Solid Films 1996, 287, 258.

(12) Marsen, B.; Miller, E. L.; Paluselli, D.; Rocheleau, R. E. Int. J. Hydrogen Energy 2007, 32, 3110.

(13) Badilescu, S.; Ashrit, P. V. Solid State Ionics 2003, 158, 187.

(14) Yang, B.; Zhang, Y. J.; Drabarek, E.; Barnes, P. R. F.; Luca, V. Chem. Mater. 2007, 19, 5664

(15) Wang, J. M.; Lee, P. S.; Ma, J. Cryst. Growth Des. 2009, 9, 2293.

(16) Widenkvist, E.; Quinlan, R. A.; Holloway, B. C.; Grennberg, H.; Jansson, U. Cryst. Growth Des. 2008, 8, 3750.

(17) Breedon, M.; Spizzirri, P.; Taylor, M.; Plessis, J. D.; Mcculloch, D.; Zhu, J.; Yu, L.; Hu, Z.; Rix, C.; Wiodarski, W.; Kalantar-zadeh, K. Cryst. Growth Des. 2010, 10, 430. 
(18) Ha, J. H.; Muralidharan, P.; Kim, D. K. J. Alloys Compd. 2009, $475,446$.

(19) Gu, Z. J.; Zhai, T, Y.; Gao, B. F.; Sheng, X. H.; Wang, Y. B.; Fu, H. B.; Ma, Y.; Yao, J. M. J. Phys. Chem. B 2006, 110, 23829.

(20) Wang, J. M.; Khoo, E.; Lee, P. S.; Ma, J. J. Phys. Chem. C 2008, $112,14306$.

(21) Hong, S. J.; Jun, H.; Borse, P. H.; Lee, J. S. Int. J. Hydrogen Energy 2009, 34, 3234.

(22) Amano, F.; Li, D.; Ohtani, B. Chem. Commun. 2010, 46, 2769.

(23) Chen, J.; Li, Chen; Song, J. L.; Sun, X. W.; Lei, W.; Deng, W. Q. Appl. Surf. Sci. 2009, 255, 7508.

(24) Di Natale, F.; Lancia, A. Ind. Eng. Chem. Res. 2007, 46, 6777.

(25) Chemseddine, A.; Bloeck, U. J. Solid State Chem. 2008, 181, 2731.

(26) Cotton, F. A.; Wilkinson, G.; Murillo, C. A.; Bochmann, M. In Advanced Inorganic Chemistry, 6th ed.; Wiley Interscience: Hoboken, NJ, 1999.

(27) Sun, M.; Xu, N. J. Mater. Res. 2000, 15, 927.

(28) Gaikwad, N. S.; Waldner, G.; Bruger, A.; Belaidi, A.; Chaqour, S. M.; Neumann-Spallart, M. J. Electrochem. Soc. 2005, 152, G411.

(29) Solarska, R.; Santato, C.; Jorand-Sartoretti, C.; Ulmann, M.; Augustynski, J. J. Appl. Electrochem. 2005, 35, 715.

(30) Ahn, K. S.; Lee, S. H.; Dillon, A. C.; Tracy, C. E.; Pitts, R. J. Appl. Phys. 2007, 101, 093524.

(31) Wang, H.; Quan, X.; Zhang, Y.; Chen, S. Nanotechnology 2008, 19, 065704.

(32) Gratzel, M. Nature 2001, 414, 338.

(33) Bak, T.; Nowotny, J.; Rekas, M.; Sorrell, C. C. Int. J. Hydrogen Energy 2002, 27, 991. 